\title{
COMPLEMENT ACTIVATION, C3 AND INTERLEUKIN-6 LEVELS AS PROGNOSTIC MARKERS IN POLYTRAUMATIZED PATIENTS
}

Syamal Modi, Mohd. Rashid, Abida Malik, Mohd. Shahid

\author{
1. Tutor. Department of Microbiology, Patna Medical College \& Hospital, Patna. \\ 2. Assistant Professor. Department of Microbiology, SMS \& R, Sharda University, Greater Noida. \\ 3. Professor. Department of Microbiology, J. N. Medical College, AMU, Aligarh. \\ 4. Reader. Department of Microbiology, J. N. Medical College, AMU, Aligarh.
}

\section{CORRESPONDING AUTHOR:}

Dr. Syamal Modi,

Road Number 11,

Rajendra nagar,

Patna-800016, Bihar.

E-mail: syamalmodi@gmail.com

Ph: 00919006378348.

ABSTRACT: CONTEXT/BACKGROUND: The management of polytraumatized patients is always challenging to the clinician due to high risk of sepsis, multi-organ failure and death. AIM: Our objective was to study Complement activation, C3 and IL-6 levels in trauma patients so that clinical outcome can be predicted for proper management of injury. SETTINGS AND DESIGN: This case-control study was conducted in the Department of Microbiology, Jawaharlal Nehru Medical College, Aligarh Muslim University, Aligarh. MATERIALS AND METHODS: 44 trauma patients and 40 healthy controls, selected on a random basis, were included in this study. Blood was collected within 24 hours and at $7^{\text {th }}$ day of injury. Complement activation was determined by Countercurrent Immunoelectrophoresis and Crossed Electrophoresis. C3 levels were measured using Single Radial Immunodiffusion. IL-6 was detected by ELISA. STATISTICAL ANALYSIS USED: Unpaired " $\mathrm{t}$ " test and Chi-square test were used to analyze the data statistically. Probability values less than 0.05 were considered significant. RESULTS: All patients showed complement activation within 24 hours of injury. Patients with Injury Severity Score (ISS) $\geq 15$ had lower C3 as compared to controls ( $p<0.001$ ) and those with ISS $<15$ ( $p<$ 0.001 ). Patients with ISS $\geq 30$ continued to have activated complement and low C3 in $2^{\text {nd }}$ week; they subsequently developed infection. Complement was inactive and C3 levels recovered in patients with ISS $<30$. Non-survivors showed lower C3 than survivors $(p<0.05)$. Patients with infection had lower C3 than those who remained free of infection $(\mathrm{p}<0.05)$. All patients with ISS $\geq 15$ showed initial elevation in IL- 6 levels. Patients with ISS $\geq 45$ had higher IL- 6 than controls $(p<0.001)$ and those with ISS $<45(p<0.05)$. Non-survivors had higher IL- 6 than survivors $(p<0.05)$. Patients who developed infection showed higher IL- 6 than those without infection ( $p<0.001)$. CONCLUSIONS: Complement activation, C3 and IL-6 levels correlated well with severity of injury and development of infection. Serial estimation of complement activation status, C3 levels and IL-6 levels are useful tools in monitoring the clinical progress of trauma patients as these parameters vary significantly with respect to the severity of injury and the development of local and systemic infection in such patients. Hence, they can be used to decide timely the course of therapeutic interventions, predict the onset of infection/septicemia and mortality in polytraumatized patients.

KEY WORDS: Complement activation, C3, Interleukin-6, Crossed electrophoresis, Countercurrent Immunoelectrophoresis, Single radial immunodiffusion, Injury Severity Score. 
INTRODUCTION: The Complement System is a cascade of over 30 activating, effector and regulatory proteins that enhance the ability of the humoral immune system to opsonize or destroy a variety of pathogens. The cascade also contributes to cellular immunity by producing peptides that promote capillary leak and leucocyte migration at sites of infection and tissue damage. It has been noted that in humans, acute blood loss and trauma activate the complement cascade and that the degree of activation correlates with injury severity, development of multiple organ failure, and death. ${ }^{[1,2]}$ Systemic complement activation has been described in soft tissue trauma, burn injury and models of myocardial, intestinal, and skeletal muscle ischemia. $[3,4]$

Trauma induced immunosuppression has generated a lot of interest in recent times because of its observed influence on the prognosis of the injured patient. The immunocompromised state that follows trauma has been demonstrated in operated and traumatized patients, and in experimental animals. Inhibition of phagocytosis and suppression of humoral and cell mediated immunity are well recognized consequences of trauma. ${ }^{[1,3,4]}$ Many of these alterations have been shown to correlate with an increased rate of sepsis in the posttraumatic and post-operative periods. [5,6]

Recently, it has become clear that a cytokine Interleukin-6, earlier known as hybridoma growth factor, is involved in systemic changes associated with tissue injury and infection. [7,8,9] IL-6 is released by damaged tissue and induces the synthesis of proteins in the liver (acute phase proteins) that protect the host against inflammatory reactions, hence has been rightly called the "alarm hormone". [10] The important role of IL-6 in inflammatory reactions led to study of its role in multiorgan failure and sepsis. [7,8,9]

IL-6 levels are found to be elevated in various diseases, in patients with multiple injuries, burns, septicemia etc. Elevated IL- 6 levels have been reported within hours of multiple trauma in humans. [11]

However, most aspects of the effects of trauma on complement function and cytokine stimulation are still under investigation. It will be worthwhile to study complement alterations and IL-6 levels in trauma patients and correlate them with the clinical outcome of injury, and study their role as prognostic markers.

MATERIALS AND METHODS: This case-control study, approved by our Institutional Ethics Committee, was conducted in the Department of Microbiology, Jawaharlal Nehru Medical College, Aligarh Muslim University, Aligarh, during the period August 2006 to December 2007. Informed consent was obtained from the patients or their relatives for participation in the study. Treatment given to the patients remained unaffected by the outcome of the study.

44 recently injured patients selected on a random basis and 40 healthy controls were included in this study. Patients with various categories of mechanical trauma (Road Traffic Accidents, firearm wounds, household injuries etc.) were included and assessed for the severity of injury by the Injury Severity Score (ISS), based on the Abbreviated Injury Scale (AIS) - 98 Revision (Association for the Advancement of Automotive Medicine, 1998) [12]. A detailed clinical history was taken at admission and physical examination was carried out to record body temperature, blood pressure, pulse rate, respiratory rate, body weight and urinary output, in addition to the extent of injury. The control group included healthy subjects with no evidence of injury, any underlying disease or chronic conditions like diabetes, hypertension, malignancy etc., as deduced by their history and clinical examination. 
$5 \mathrm{ml}$ blood was collected by venepuncture from each patient within 24 hours of injury (first sample) and a second sample on the $7^{\text {th }}$ day following injury. Blood was also collected on two occasions one week apart from the members of the control group. Serum was separated and stored at $-20^{\circ} \mathrm{C}$ till further tested. Complement activation was studied using Countercurrent Immunoelectrophoresis [13] using anti-C3 antiserum (Sigma-Aldrich Ltd, USA). Presence of two lines in between the antigen - antibody wells was considered to indicate activated complement and the two lines were taken to be of C3 and C3b split product (Image 1). The results were confirmed by Crossed Electrophoresis [14] wherein the presence of two peaks, corresponding to C3 and C3b complement fraction, indicated complement activation (Image 2). Presence of a single line in Countercurrent Immunoelectrophoresis and a single peak in Crossed Electrophoresis indicated inactive complement. C3 levels in the sera of patients and controls were measured by Single Radial Immunodiffusion [15] test (Image 3) using anti-C3 antiserum. Detection and quantitative measurement of IL-6 was done using AviBion Human IL-6 ELISA kit (Orgenium Laboratories, Finland).

All the patients were monitored in the post-injury period for the following clinical signs and symptoms of septicemia, noting only their presence or absence without quantifying them: fever, wound infection, chest infection, subphrenic or pelvic abscess, renal failure, mental disorientation, bleeding diathesis and features of shock. Blood culture was performed whenever required to confirm septicemia. Wound swab culture was done to isolate the organism causing wound infection.

Results are expressed as complement status: activated / inactive; C3 levels: $\mathrm{mg} / \mathrm{dl} \pm$ standard deviation; IL-6 levels: $\mathrm{pg} / \mathrm{ml} \pm$ standard deviation.

Statistical analysis was done using the unpaired " $\mathrm{t}$ " test and Chi-square test.

Probability values less than 0.05 were considered significant.

RESULTS: Males (86.4\%) were found to be involved in mechanical trauma more frequently than females $(13.6 \%)$, and this difference was statistically significant $(\mathrm{p}<0.05)$. Maximum patients (40.9\%) belonged to the age group 30-40 years indicating that this age group was more prone to mechanical injuries. Overall, $34(77.3 \%)$ patients belonged to age $<50$ years (Table 1 ).

The patients were grouped on the basis of the Injury Severity Score (ISS). Majority of patients $(\mathrm{n}=24,54.5 \%)$ had ISS $30-45,8$ patients $(18.2 \%)$ had ISS 15-30, 6 (13.6\%) had ISS 45 $60,4(9.1 \%)$ had ISS $\geq 60$ while 2 patients $(4.5 \%)$ had ISS $<15$ (Table 2 ).

The mean C3 levels of patients were found to decrease with the increase in the severity of mechanical trauma. Mean C3 levels of patients with ISS $<15$ were $92.2 \pm 28.2 \mathrm{mg} / \mathrm{dl}$ and $131.9 \pm 24.2 \mathrm{mg} / \mathrm{dl}$ in the $1^{\text {st }}$ and $2^{\text {nd }}$ serum samples respectively. Patients with ISS $30-45$ had mean C3 levels of $44.5 \pm 26.4 \mathrm{mg} / \mathrm{dl}$ and $82.7 \pm 42.3 \mathrm{mg} / \mathrm{dl}$ respectively in $1^{\text {st }}$ and $2^{\text {nd }}$ samples. In patients with ISS $\geq 60$, the mean C3 levels were $15.5 \pm 4.3 \mathrm{mg} / \mathrm{dl}$ in $1^{\text {st }}$ samples and $38.9 \pm 9.9$ $\mathrm{mg} / \mathrm{dl}$ in $2^{\text {nd }}$ samples.

The $1^{\text {st }}$ sample mean C3 levels in patients with ISS $\geq 15$ were significantly lower as compared to controls $(\mathrm{p}<0.001)$ whereas those with minor injuries (ISS $<15$ ) had $1^{\text {st }}$ sample mean C3 levels comparable with the control mean C3 level. Complement was found to be activated in the $1^{\text {st }}$ samples of all patients irrespective of injury severity whereas complement was found inactive in controls. In the $2^{\text {nd }}$ samples, complement was activated and mean C3 levels continued to be low only in patients with ISS $\geq 30$ ( $p<0.001)$. These patients were found to develop wound infection/septic complications during the course of treatment. Patients with ISS $<30$ showed inactive complement and recovery of C3 levels in their $2^{\text {nd }}$ samples (Figure 1). 
Mean IL-6 levels were found to increase with the increase in ISS (Figure 2).

All patients with ISS $\geq 15$ showed elevation in mean IL-6 levels in $1^{\text {st }}$ samples. Those with ISS $\geq 45$ had significantly higher IL-6 levels as compared to controls ( $p<0.001)$ as well as the patients with ISS $<45(\mathrm{p}<0.05)$. The $1^{\text {st }}$ sample IL- 6 level in the patients with ISS $<15$ was comparable with the control mean IL-6 level. The $2^{\text {nd }}$ sample IL-6 levels were raised in all patients regardless of their ISS. However, patients with ISS $\geq 45$ showed significantly higher $2^{\text {nd }}$ sample IL-6 levels in comparison to controls ( $p<0.001)$ as well as those with ISS $<45$ ( $p<$ 0.001). These patients were subsequently found to develop wound infection with or without septicemia. Thus, low C3 and high IL-6 levels were found to correlate well with the severity of injury and the development of infection in trauma patients.

16 (36.4\%) trauma patients who developed septicemia and died had $1^{\text {st }}$ sample mean C3 level of $24.7 \pm 16.1 \mathrm{mg} / \mathrm{dl}$ and $2^{\text {nd }}$ sample mean C3 level of $30.1 \pm 11.7 \mathrm{mg} / \mathrm{dl}$. This difference was significant as compared to controls $(p<0.001$ ). Their mean IL-6 values increased from $460.9 \pm 191.5 \mathrm{pg} / \mathrm{ml}$ in the $1^{\text {st }}$ sample to $1046.4 \pm 306.9 \mathrm{pg} / \mathrm{ml}$ in the $2^{\text {nd }}$ sample. This rise in mean IL-6 was statistically significant. The mean duration of hospital stay among these patients (15.2 \pm 1.9 days) was also much longer as compared to those who survived.

Two patients who had septicemia but who survived had lower mean C3 levels as well as higher mean IL-6 levels, as compared to controls. 18 (40.9\%) patients who developed wound infection but survived also showed lower mean C3 levels and higher mean IL-6 levels than controls. Their mean C3 levels were $29.0 \pm 20.0 \mathrm{mg} / \mathrm{dl}$ and $69.4 \pm 36.9 \mathrm{mg} / \mathrm{dl}$ in $1^{\text {st }}$ and $2^{\text {nd }}$ samples respectively; both these values were statistically significant when compared to controls ( $\mathrm{p}<0.001$ ).Their mean IL-6 levels increased from $340.0 \pm 419.1 \mathrm{pg} / \mathrm{ml}$ to $501.5 \pm 183.6 \mathrm{pg} / \mathrm{ml}$, the rise was statistically significant in comparison with the control mean IL-6 levels $(\mathrm{p}<0.001)$.

$8(18.2 \%)$ trauma patients who did not develop any infection had mean C3 levels of $46.5 \pm 18.7 \mathrm{mg} / \mathrm{dl}$ and $70.2 \pm 14.8 \mathrm{mg} / \mathrm{dl}$ respectively in their $1^{\text {st }}$ and $2^{\text {nd }}$ samples, this difference was significant as compared to controls $(\mathrm{p}<0.001)$. Their $1^{\text {st }}$ and $2^{\text {nd }}$ sample mean IL-6 levels were $174.3 \pm 95.0 \mathrm{pg} / \mathrm{ml}$ and $2015 . \pm 57.6 \mathrm{pg} / \mathrm{ml}$, these were significantly higher than controls (p $<0.001$ ). The mean duration of hospital stay was the longest among the non-survivors and the shortest among the patients who remained free of infection.

Overall, the $1^{\text {st }}$ sample mean C3 levels of survivors were not significantly different from the $1^{\text {st }}$ sample mean C3 levels of the non-survivors. However, the $2^{\text {nd }}$ sample mean C3 levels of the non-survivors were significantly lower than the survivors $(\mathrm{p}<0.05)$. The mean IL- 6 of $1^{\text {st }}$ as well as $2^{\text {nd }}$ samples in non-survivors was significantly higher than survivors $(\mathrm{p}<0.05)$. Also, patients who developed infection were found to have significantly lower mean C3 levels and higher IL-6 levels in the $2^{\text {nd }}$ samples than the patients who did not develop any infection (Figures 3 and 4). The mean duration of hospital stay among the various groups of trauma patients also correlated well with the mean C3 and IL-6 levels.

Bacterial infection was found to occur in 36 out of 44 (81.8\%) trauma patients. 18 out of $44(40.9 \%)$ patients had positive blood culture as well as wound swab culture. 18 patients $(40.9 \%)$ were positive only for wound swab culture whereas blood culture was negative in these patients. $8(18.2 \%)$ patients did not develop any infection.

The most common isolate amongst the trauma patients was Staphylococcus aureus (37.0\%) followed by Escherichia coli (18.5\%), Coagulase negative Staphylococci, Pseudomonas species and Klebsiella species (11.1\% each), Streptococcus pyogenes $(7.4 \%)$ and Enterococcus faecalis (3.7\%) (Table 3). 
DISCUSSION: The general immune competence of a patient with severe trauma is important in determining the final outcome. The complement system has evolved to enable the body to defend itself immediately against microbial invasion in a relatively non-specific manner. The complement system is one of the principal effectors of the humoral arm of the immune system and is important in defense against microbial invasion. [16,17]

Complement activation is generally beneficial to the host but in patients who develop infections following injury, profound and persistent complement activation leads to consumption and depletion of essential components of complement, and the necessary functions of chemotaxis, opsonization and microbial cell lysis are hampered. This is called consumptive opsinopathy which occurs in severe bacterial infections such as those which occur in the immediate post-injury period. ${ }^{[18]}$

An established parameter in this post-traumatic immunosuppression could be of great value to the clinician in predicting the outcome of the injury in the traumatized patients with a reasonable degree of accuracy especially since immunosuppression is reported to correlate well with the occurrence of septic complications in these patients. The relationship in humans of acute injury to complement activation (as measured by a decrease in circulating activity) or the appearance in blood of activation products has been reported. [19] Extensive amounts of nonviable tissue have been found to be associated with significant depletion of C3, C4 and C5 within 24 hours after injury. [19]

A correlation appears to exist between the volume of nonviable tissue formed by injury and complement depletion. A minor trauma produces a less pronounced depletion of C3 compared to patients with extensive amounts of nonviable tissue. [19] Serum C3 levels are found to exhibit an inverse relation with the severity of injury. [20]

We observed complement activation and a fall in serum C3 levels within hours of injury. The mean C3 levels of patients were found to decrease with the increase in the severity of mechanical trauma. Mean C3 levels in patients with ISS $\geq 15$ were significantly lower as compared to those with ISS $<15$. All patients showed initial complement activation irrespective of injury severity. In the $2^{\text {nd }}$ post-injury week, complement was activated and mean C3 levels continued to be low only in patients with ISS $\geq 30$. These patients were found to develop wound infection with or without septicemia during the course of treatment. Patients with ISS $<30$ showed inactive complement and recovery of C3 levels in their $2^{\text {nd }}$ samples. The non-survivors showed significantly lower C3 levels than the survivors in their $2^{\text {nd }}$ samples $(p<0.05)$. Patients who developed infection also had mean C3 levels significantly lower than those who remained free of infection $(p<0.05)$.

Cytokine stimulation has been observed within hours of injury. High levels of IL-6 are seen in various diseases, in patients with multiple injuries, burns, septicemia etc. The important role of IL-6 in inflammatory reactions led to study of its role in multiorgan failure and sepsis. [9] Increased levels of IL- 6 within hours of injury have been reported by several workers. [8,9] Persistence of high IL-6 levels in relation to sepsis has also been observed. [7,21] Several workers have observed a positive correlation between circulating IL- 6 levels and the magnitude of injury. [11,22,23]

We also found raised IL-6 levels within hours of trauma. All patients with ISS $\geq 15$ showed initial elevation in mean IL-6 levels. Those with more severe injuries (ISS $\geq 45$ ) had significantly higher IL-6 levels as compared to the patients with less severe injuries (ISS < 45). The $2^{\text {nd }}$ sample IL-6 levels were raised in all patients regardless of their ISS. However, patients with ISS $\geq 45$ showed significantly higher $2^{\text {nd }}$ sample IL- 6 levels in comparison to those with ISS 
$<45$. These patients were subsequently found to develop wound infection with or without septicemia. Non-survivors had higher mean IL-6 levels than survivors in both samples. Also, patients who developed infection showed significantly higher IL-6 levels in $2^{\text {nd }}$ samples than those without infection.

CONCLUSIONS: Complement activation, C3 and IL-6 levels correlated well with severity of injury and development of infection. Serial estimation of complement activation status, C3 levels and IL-6 levels are useful tools in monitoring the clinical progress of trauma patients as these parameters vary significantly with respect to the severity of injury and the development of local and systemic infection in such patients.

Hence, they can be used to decide timely the course of therapeutic interventions, predict the onset of infection/septicemia and mortality in polytraumatized patients.

ACKNOWLEDGEMENTS: The authors wish to thank the Indian Council of Medical Research, New Delhi, for providing financial assistance for this study.

\section{REFERENCES:}

1. Sharma DK, Sarda AK, Bhalla SA, Goyal A, Kulshreshta VN. The effect of recent trauma on serum complement activation and serum C3 levels correlated with the injury severity score. IJMM 2004; 22: 147-152.

2. Hietbrink F, Koenderman L, Rijkers GT, Leenen LPH. Trauma: the role of the innate immune system. World J of Em Surg 2006; 1:15.

3. Catania RA, Chaudry IH. Immunological consequences of trauma and shock. Ann Acad Med Singapore 1999; 28: 120-132.

4. Hecke F, Schmidt U, Kola A, Bautsch W, Klos A, Kohl J. Circulating complement proteins in multiple trauma patients - correlation with injury severity, development of sepsis and outcome. Crit Care Med 1997; 25: 2015-2024.

5. Huber-Lang MS, Younkin EM, Sarma JV, Mc Guire SR, Lu KT, Guo RF, et al. Complement induced impairment of innate immunity during sepsis. J Immunol 2002; 169: 3223-3231.

6. Dofferhoff AS, de Jong HJ, Bom VJ, van der Meer J, Limburg PC, de Vries-Hospers HG et al. Complement activation and the production of inflammatory mediators during the treatment of severe sepsis in humans. Scand J Infect Dis 1992; 24: 197-204.

7. Selberg O, Hecker H, Martin M, Klos A, Bautsch W, Kohl J. Discrimination of sepsis and systemic inflammatory response syndrome by determination of circulating plasma concentrations of procalcitonin, protein complement 3a, and interleukin-6. Crit Care Med 2000; 28: 2793-2798.

8. Nast-Kolb D, Waydhas C, Gippner-Steppert C, Schneider I, Trupka A, Ruchholtz S et al. Indicators of Post-traumatic Inflammatory Response correlate with Organ Failure in patients with multiple injuries. J Trauma 1997; 42: 446-455.

9. Martin C, Boisson C, Haccoun M, Thomachot L, Mege JL. Patterns of cytokine evolution (tumor necrosis factor-alpha and interleukin-6) after septic shock, hemorrhagic shock, and severe trauma. Crit Care Med 1997; 25: 1813-1819.

10. Fey GH, Gauldie J. The acute phase response of liver in inflammation. In: Popper H, Schaffner F, editors. Progress in liver disease. $9^{\text {th }}$ ed. Philadelphia: WB Saunders; 1990. p. 89. 
11. Gebhard F, Pfetsch H, Steinbach G, Streker W, Kinzl L, Bruckner B. Is interleukin-6 an early marker of injury severity following major trauma in humans? Arch Surg 2000; 135: 291-295.

12. Committee on injury scaling. The AIS-1998 Revision. Association for the Advancement of Automative Medicine, Des Plaines, Illinois, USA 60018.

13. Rojas-Espinosa O, Estrada-Parra S, Serrano-Miranda E, Saul A, Latapi F. Antimycobacterial antibodies in diffuse lepromatous leprosy detected by counterimmunoelectrophoresis. Int J Lepr OtherMycobact Dis 1976; 44: 448-452.

14. Laurell CB. Antigen-Antibody crossed electrophoresis Anlyt Biochem. 1965; 10: 358361.

15. Mancini G, Carbonara AO, Heremans JF. Immunochemical quantitation of antigens by single radial immunodiffuion. Immunochemistry 1965; 2: 235-254.

16. Fischer $\mathrm{M}$, Prodeus $\mathrm{A}$, Nicholson-Weller $\mathrm{A}$, et al. Increased susceptibility to endotoxin shock in complement C3-and C4 deficient mice is corrected by C1 inhibitor replacement. J Immunol 1997; 159: 976-982.

17. Brown, JS, Hussell T, Gilliland SM, et al. The classical pathway is the dominant complement pathway required for innate immunity to streptococcus pneumoniae infection in mice. Proc Natl Acad Sci USA 2002, 99:16969-16974.

18. Peakman M, Senaldi G, Vergani D. Assessment of complement activation in clinical immunology laboratories: Time for reappraisal? J Clin Pathol 1989; 42: 1018-1025.

19. Younger JG, Sasaki N, Waite MD, Murray HN, Saleh EF, Ravage ZA, et al. Detrimental effects of complement activation in haemorrhagic shock. J Appl Physiol 2001; 90: 441-446.

20. Weiser MR, Williams JP, Moore Jr FD, Kobzik L, Ma M, Hetchman HB, et al. Reperfusion injury of ischaemic skeletal muscle is mediated by natural antibody and complement. J Exp Med 1996; 183: 2343-2348.

21. Gaini S, Kold kjaer OG, Pederson C, Pederson SS. Procalcitonin, lipopoly saccharidebinding protein, interleukin- 6 and C-reactive protein in community acquired infections and sepsis: a prospective study. Critical Care 2006; 10: 53-62.

22. Yamgur Y, Ozturk H, Unaldi M, Gedik E. Relation between severity of injury and the early activation of interleukins in multiple injured patients. Eur Surg Res 2005; 37: 360-364.

23. Biffl WL, Moore EE, Moore FA, Peterson VM. Interluekin-6 in the injured patient: Marker of injury or mediator of inflammation? Ann Surg 1996; 224: 647-664. 
Table 1: Age and Sex distribution of patients

\begin{tabular}{cccc}
\hline \multirow{2}{*}{ Age (years) } & \multicolumn{2}{c}{ Number of patients } & \multirow{2}{*}{ Total } \\
\cline { 2 - 3 } & Male & Female & \\
\hline$<10$ & $0(0)$ & $0(0)$ & $0(0)$ \\
$10-20$ & $6(100.0)$ & $0(0)$ & $6(13.6)$ \\
$20-30$ & $8(100.0)$ & $0(0)$ & $8(18.2)$ \\
$30-40$ & $16(88.9)$ & $2(11.1)$ & $18(40.9)$ \\
$40-50$ & $2(100.0)$ & $0(0)$ & $2(4.5)$ \\
$50-60$ & $2(50.0)$ & $2(50.0)$ & $4(9.1)$ \\
$60-70$ & $0(0)$ & $0(0)$ & $0(0)$ \\
$>70$ & $4(66.7)$ & $2(33.3)$ & $6(13.6)$ \\
\hline Total & $\mathbf{3 8 ( 8 6 . 4 )}$ & $\mathbf{6 ( 1 3 . 6 )}$ & $\mathbf{4 4 ( 1 0 0 . 0 )}$ \\
\hline
\end{tabular}

Figures in parentheses indicate percentage

Table 2: Distribution of patients based on the Injury Severity Score (ISS)

\begin{tabular}{cccc}
\multirow{2}{*}{ ISS } & \multicolumn{2}{c}{ Number of patients } & \multirow{2}{*}{ Total } \\
\cline { 2 - 3 } & Male & Female & \\
\hline$<15$ & $2(100.0)$ & $0(0)$ & $2(4.5)$ \\
$15-30$ & $8(100.0)$ & $0(0)$ & $8(18.2)$ \\
$30-45$ & $20(83.3)$ & $4(16.7)$ & $24(54.5)$ \\
$45-60$ & $4(66.7)$ & $2(33.3)$ & $6(13.6)$ \\
$\geq 60$ & $4(100.0)$ & $0(0)$ & $4(9.1)$ \\
\hline Total & $\mathbf{3 8 ( 8 6 . 4 )}$ & $\mathbf{6 ( 1 3 . 6 )}$ & $\mathbf{4 4 ( 1 0 0 . 0 )}$ \\
\hline
\end{tabular}

Figures in parentheses indicate percentage

Table 3: Bacterial isolates in trauma patients

\begin{tabular}{|c|c|c|c|}
\hline Organism & Total isolates & Wound swab culture & Blood culture \\
\hline S. aureus & $20(37.0)$ & $14(70.0)$ & $6(30.0)$ \\
\hline CONS & $6(11.1)$ & $6(100.0)$ & $0(0)$ \\
\hline S. pyogenes & $4(7.4)$ & $2(50.0)$ & $2(50.0)$ \\
\hline E. faecalis & $2(3.7)$ & $0(0)$ & $2(100.0)$ \\
\hline E. coli & $10(18.5)$ & $6(60.0)$ & $4(40.0)$ \\
\hline Klebsiella sp. & $6(11.1)$ & $4(66.7)$ & $2(33.3)$ \\
\hline Pseudomonas sp. & $6(11.1)$ & $4(66.7)$ & $2(33.3)$ \\
\hline Total & 54 & 36 & 18 \\
\hline
\end{tabular}

Figures in parentheses indicate percentage 


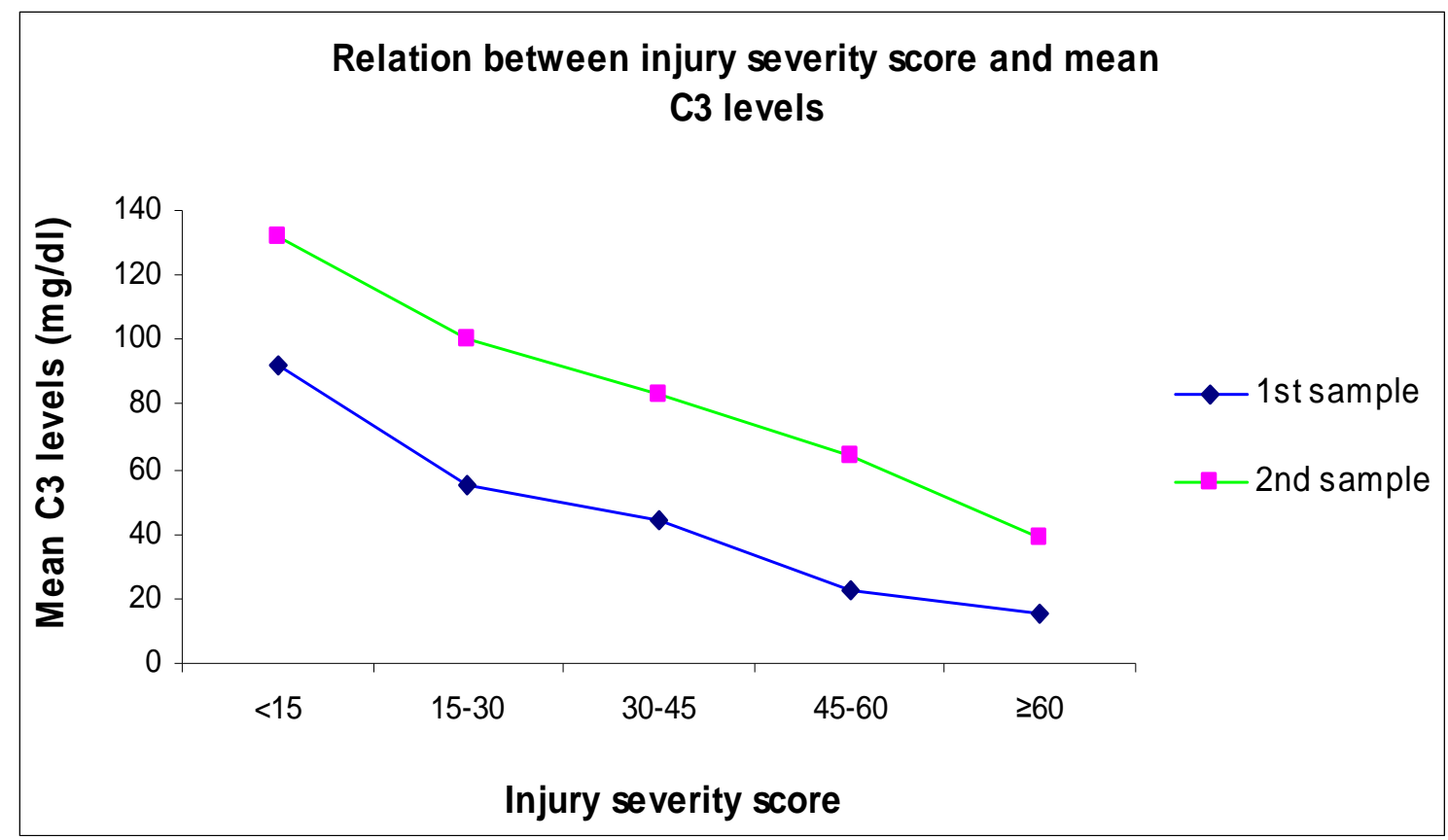

Figure 1

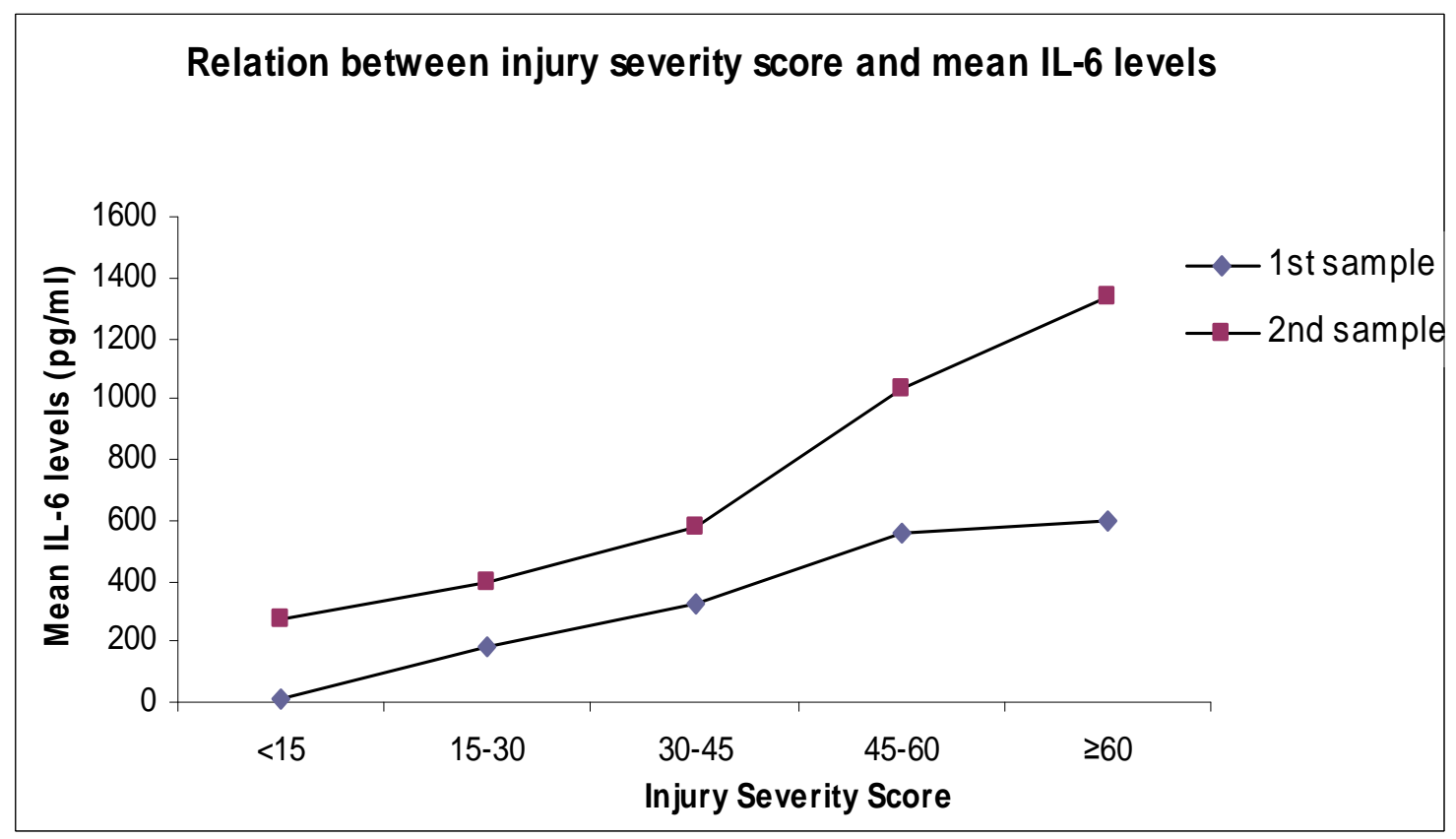

Figure 2 


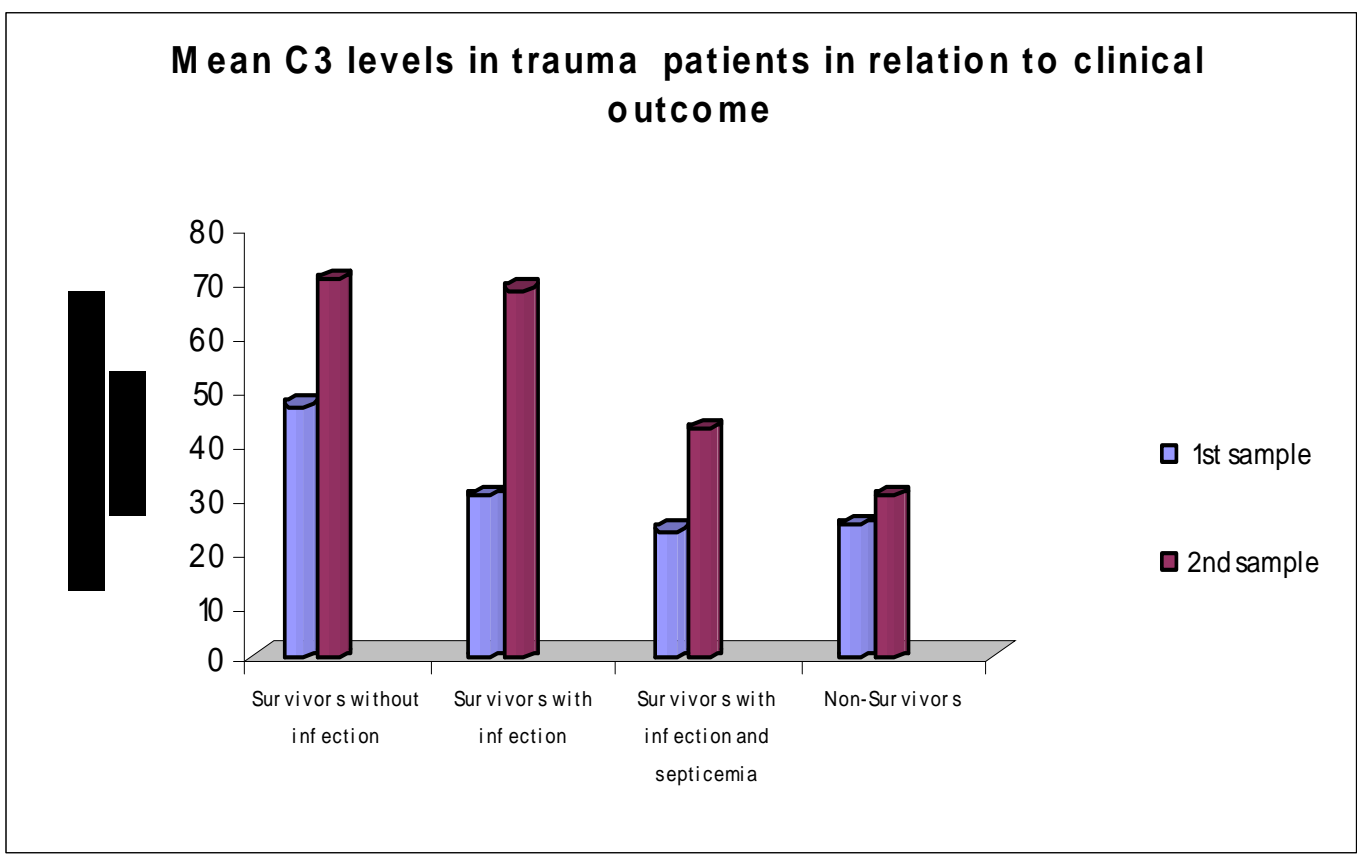

Figure 3

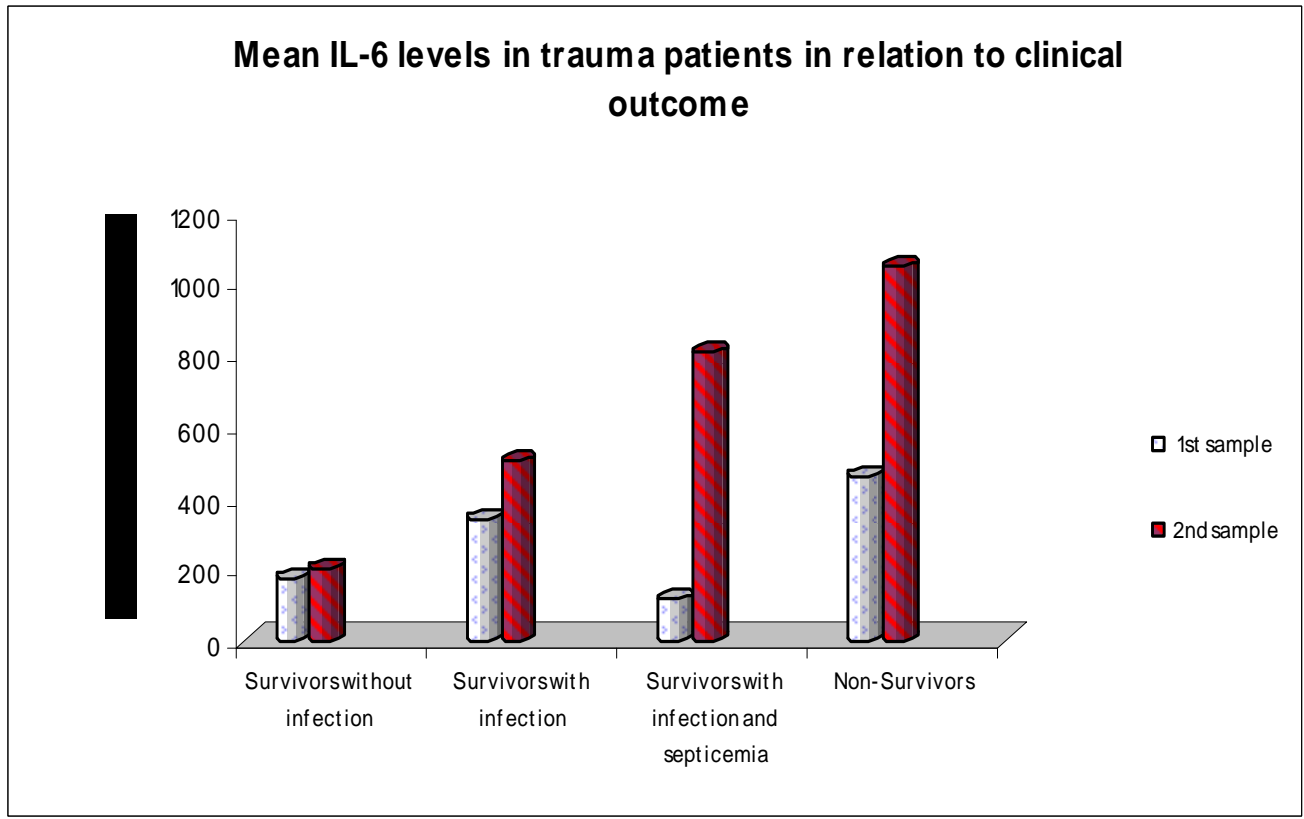

Figure 4 


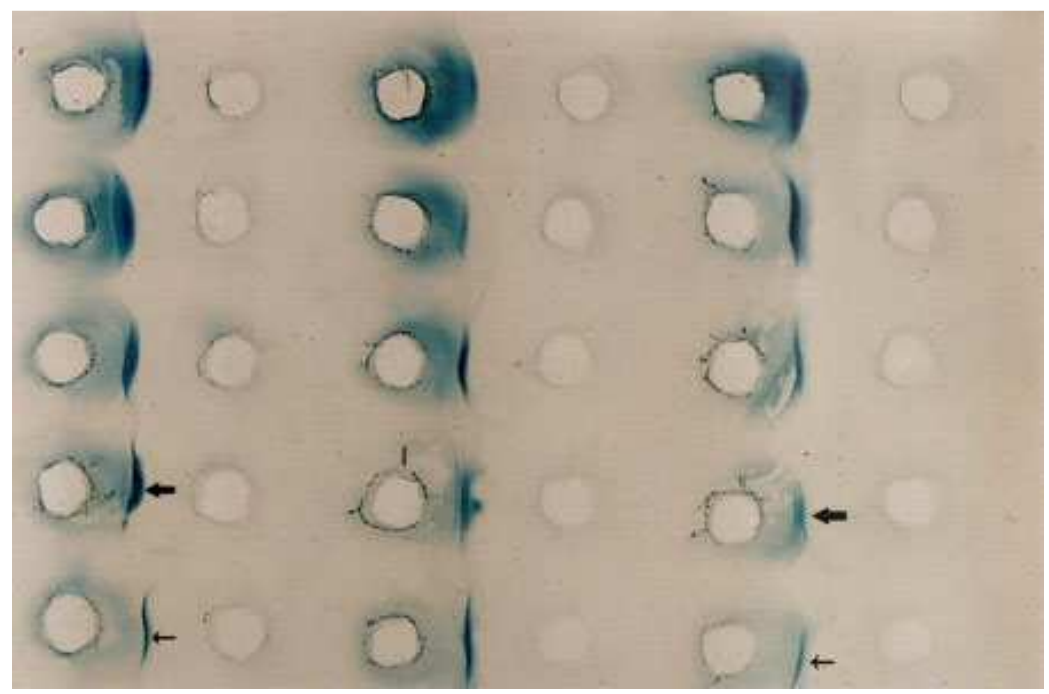

Countercurrent Immunoelectrophoresis to detect complement activation $\checkmark=2$ lines indicating activated complement $\leftarrow=$ Single line indicating inactive complement

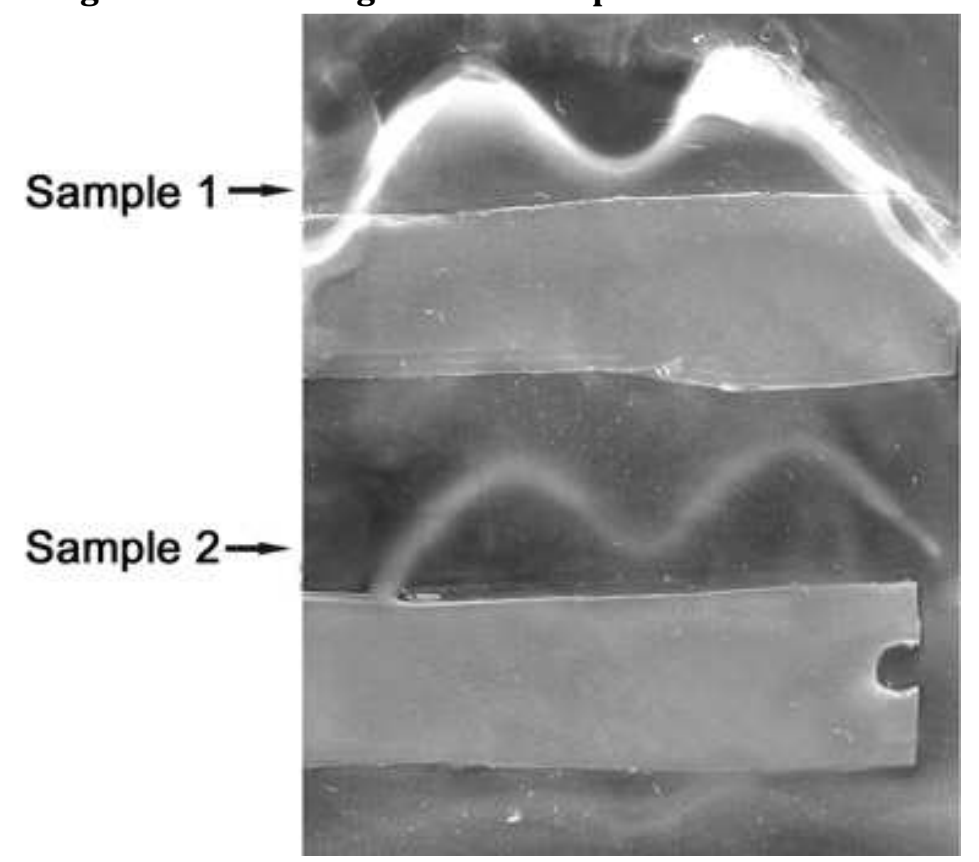

Figure 2: Crossed Electrophoresis to detect complement activation Presence of 2 peaks of $\mathrm{C} 3$ and $\mathrm{C} 3 \mathrm{~b}$ indicates activated complement 


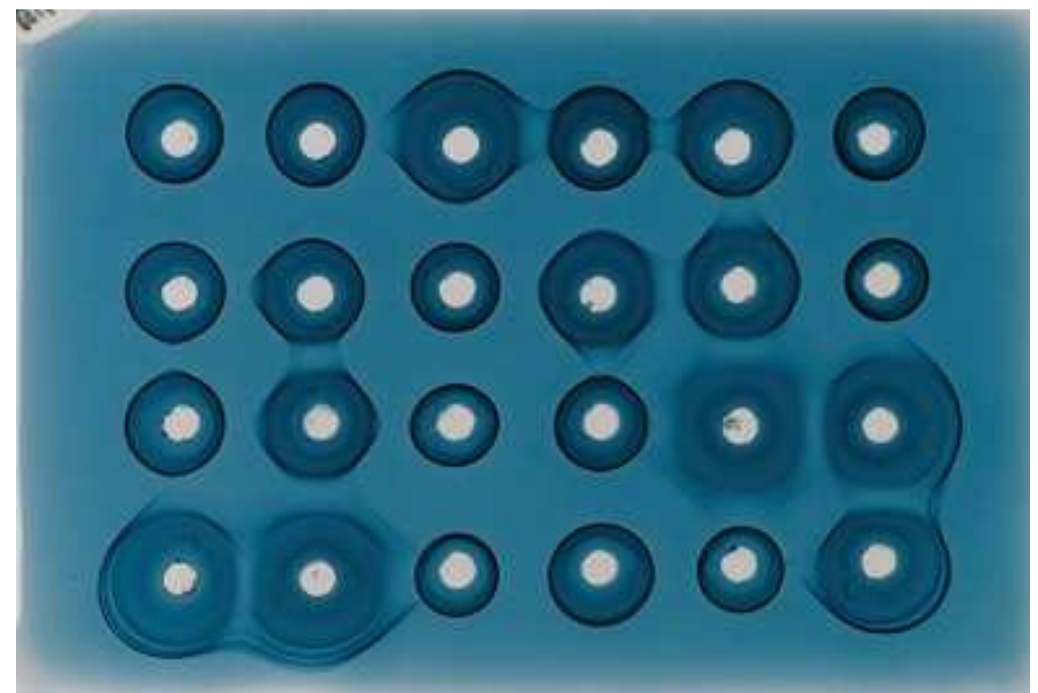

Figure 3: Single Radial Immunodiffusion test to estimate C3 levels 